\title{
Analysis of Mechanical Properties of Hybrid Burmese Silk Orchid and Glass Fibers Composite Material
}

\author{
Lakshmanan $\mathbf{V}^{1}$, Ramesh Kumar $\mathbf{C}^{2}$ and Gopal $\mathbf{P}^{1^{\star}}$ \\ ${ }^{1}$ Department of Mechanical Engineering, BIT campus, Anna University, Tiruchirappalli, Tamilnadu, India \\ ${ }^{2}$ School of Mechanical and Building Sciences, VIT University, Vellore, Tamilnadu, India
}

\begin{abstract}
The mechanical properties of vinyl ester matrix composites reinforced with hybrid burmese silk orchid-glass fibres were evaluated. There are indications that the incorporation of both fibres into a single matrix which is vinyl ester resin will stabilize mechanical properties and lowering manufacturing costs. In this research the tensile strength and flexural strength were studied for composite material reinforced with hybrid fibres for burmese silk orchid and glass fibre. These fibres were mixed with vinyl ester resin in reinforcement percentage $(5 \%)$ with different length of burmese silk orchid fibre $(20 \mathrm{~mm}, 30 \mathrm{~mm}, 40 \mathrm{~mm})$ and the effect on the above mechanical properties will be study. It has shown an improvement in these mechanical properties after reinforcement by fibres the value of mechanical properties will increase with increasing percentage of reinforcement.
\end{abstract}

Copyright@2015 STAR Journal, Wollega University. All Rights Reserved.

\author{
Article Information \\ Article History: \\ Received : 03-04-2015 \\ Revised : 23-06-2015 \\ Accepted : 26-06-2015 \\ Keywords: \\ Burmese silk orchid fibers \\ Glass fibers \\ Vinyl ester resin \\ Tensile strength \\ *Corresponding Author: \\ Gopal P \\ E-mail: gopalpp@gmail.com
}

\section{INTRODUCTION}

Composite materials are designed to combine desirable characteristics of two or more distinct materials. The reinforcement can be synthetic (e.g. glass, carbon, boron and aramid) or of natural sources (e.g. curaua, sisal, jute, piassava, hemp, coir, flax and banana). The main advantages of using natural fibers are: abundance and renewability, low cost, non-abrasiveness, easy processing, non-toxicity, high flexibility, acoustic insulation and low density (Ali et al., 2012) On the other hand, there are some drawbacks such as their poor mechanical properties and high moisture absorption. The latter is due to their hydrophilic nature that is detrimental to many properties, including dimensional stability (Daiane et al., 2013). Nevertheless, some composite components (e.g. for the automotive sector).

Properties of composites are strongly dependent on the properties of their constituent materials, their distribution and the interaction among them. The composite properties may be the volume fraction sum of the properties of the constituents or the constituents may interact in a synergistic way resulting in improved or better properties. Apart from the nature of the constituent materials, the geometry of the reinforcement (shape, size and size distribution) influences the properties of the composite to a great extent. The concentration distribution and orientation of the reinforcement also affect the properties (Girisha et al., 2012).

The shape of the discontinuous phase (which may by spherical, cylindrical, or rectangular cross-sanctioned prisms or platelets), the size and size distribution (which controls the texture of the material) and volume fraction determine the interfacial area, which plays an important role in determining the extent of the interaction between the reinforcement and the matrix (Jose et al., 2012).

Concentration, usually measured as volume or weight fraction, determines the contribution of a single constituent to the overall properties of the composites. It is not only the single most important parameter influencing the properties of the composites, but also an easily controllable manufacturing variable used to alter its properties (Saha et al., 2012). In the present study, The mechanical properties of vinyl ester matrix composites reinforced with hybrid burmese silk orchid-glass fibres were evaluated.

\section{MATERIALS AND METHODS \\ Mould Box}

Medium-density fibreboard (MDF) is an engineered wood product made by breaking down hardwood or softwood residuals into wood fibers, often in a defibrator, combining it with wax and a resin binder, and forming panels by applying high temperature and pressure. MDF is generally denser than plywood. It is made up of separated fibers, but can be used as a building material similar in application to plywood. It is stronger and much denser than particle board.

MDF density is typically between $500 \mathrm{~kg} / \mathrm{m}^{3}\left(31 \mathrm{lbs} / \mathrm{ft}^{3}\right)$ and $1000 \mathrm{~kg} / \mathrm{m}^{3}\left(62 \mathrm{lbs} / \mathrm{ft}^{3}\right)$. The range of density and classification as Light or Standard or High density board is a misnomer and confusing. Density of board when evaluated in relation to density of the fiber that goes into making of the panel is important. A thick MDF panel at a 
Lakshmanan, Ramesh Kumar and Gopal

density of $700-720 \mathrm{~kg} / \mathrm{m}^{3}$ may be considered as high density in the case of softwood fiber panels whereas a panel of the same density made of hard wood fibers is not regarded as so.

Here we are using hand lay-up method of moulding to make composite materials. Then we are making a moulding box in MDF material boards with the required dimensions for fabricating the specimen size and the specification of the board are given in Table 1. Three no.of boards are used for making the mould box. Those are namely Top board, Middle board and Base board. Here the top and bottom or base boards are similar dimensions and then the middle board only having different from others as shown in figure 1.

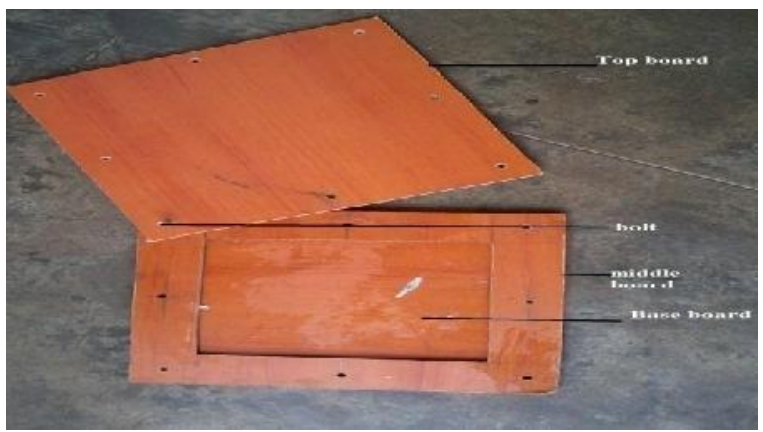

Figure 1: Mould box construction

Table 1: specifications of mould box

\begin{tabular}{ll}
\hline Board dimension $(\mathrm{L} \times \mathrm{W} \times \mathrm{T})$ & $300 \times 300 \times 5 \mathrm{~mm}$ \\
Die Cavity Dimension & $200 \times 200 \times 5 \mathrm{~mm}$ \\
Area & $0.04 \mathrm{~m}^{2}$ \\
Volume & $0.2 \mathrm{~cm}^{3}$ \\
No.of bolts and nuts & 8 \\
Size of bolts andnuts & $8 \mathrm{~mm}$ \\
Material & MDF \\
Colour & Inside - white and \\
OHP Sheet Size $(\mathrm{L} \times \mathrm{W} \times \mathrm{T})$ & Outside - Brown \\
No.of boards & $300 \times 210 \times 1 \mathrm{~mm}$ \\
\hline
\end{tabular}

\section{Raw Material Collection}

A new fiber for reinforcing with polymers named as aathi (Tamil), Burmese silk orchid (English) and scientific name is Bauhinia racemosa was used. Bauhinia trees typically reach a height of $6-12 \mathrm{~m}$ and their branches spread 3-6 m outwards. The lobed leaves usually are 10$15 \mathrm{~cm}$ across as shown in figure 2 and 3 . The stems of Burmese silk orchid fiber were collected from Hogenakkal, krishnagiri district ,Tamilnadu. The raw material (Burmese silk orchid bark) is manually extracted from the Burmese silk orchid tree using cutters and knifes.

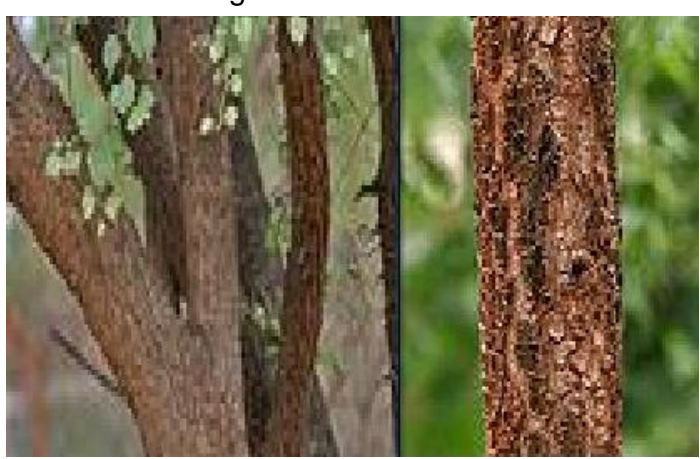

Figure 2: Soaking of bark
Sci. Technol. Arts Res. J., April-June 2015, 4(2): 241-246

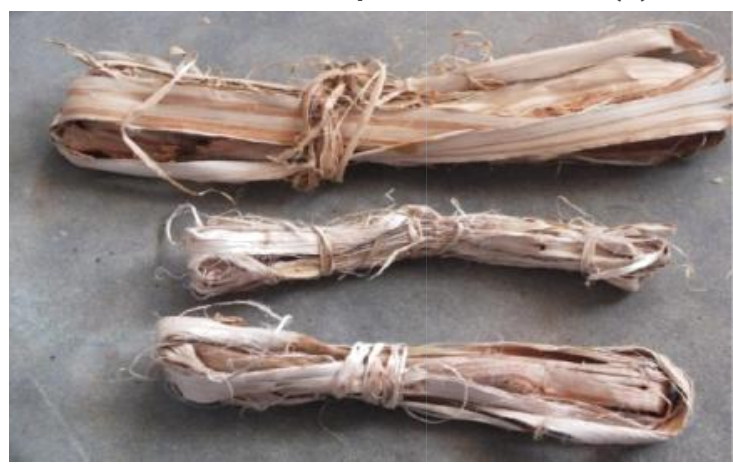

Figure 3: Modified bark

\section{Soaking of Bark}

The modified bark from the tree is not easy for extraction finest fiber because it has very dry stage and hard. So we are soaking the fiber with the water more than 24 hours. Then the soaked bark take out from the bucket which is used for soaking the bark. Due to soaking, the molecular forces acting with the bark will be decreased. They became soft and both inner and outer layers got detached. So that we can easily extracted fiber from the bark.

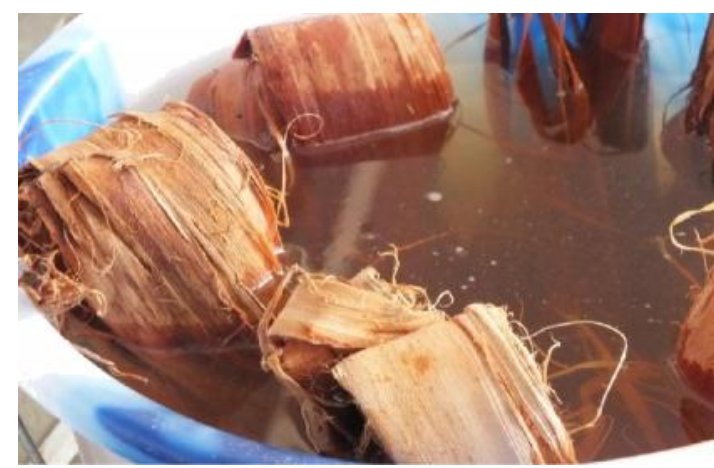

Figure 4: Soaking of bark

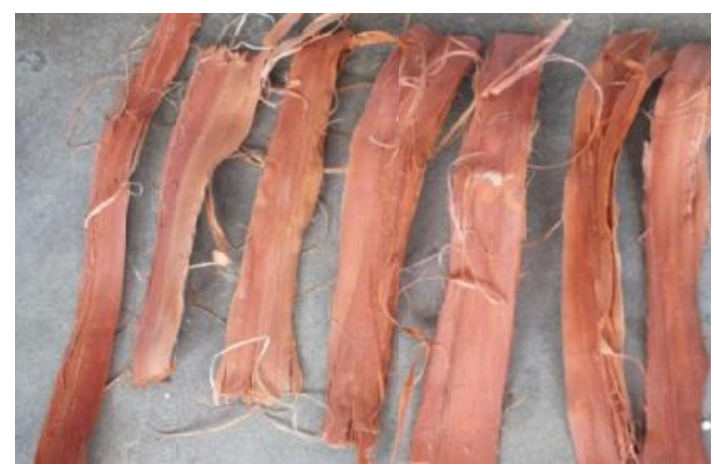

Figure 5: Modified bark

After soaking the bark of the tree has more than one meter length. So that we were cut into more number of small size of barks for easy to extract the finest fiber from the Burmese silk orchid bark. After modified bark has 30 $\mathrm{cm}$ length and $20 \mathrm{~cm}$ dia as shown in figures 4 and 5 .

\section{Extraction of Fibre}

After modification of bark, then we are extracting finest fiber from the bark manually using knifes with the required lengths and diameters. The extracted fiber has $30 \mathrm{~cm}, 20$ $\mathrm{cm}, 10 \mathrm{~cm}$ and $5 \mathrm{~cm}$ lengths \& $1 \mathrm{~cm}$ diameter. These sizes 


\section{Lakshmanan, Ramesh Kumar and Gopal}

of finest natural fibers are most convenient for reinforcing with polymers. One modified bark will given large quantity of fiber with less weight. The fig 6 and 7 shows the finest natural Burmese silk orchid fiber. The extracted fiber has some moisture content in their inner and outer layers so we should be dehydrate the extracted fiber. In order to dehydrate the fiber, it is kept $32^{\circ} \mathrm{C}$ in sun light over $2-3$ day.

\section{Collection of Glass Fibre}

Natural fibers are not convenient for load applications because of the natural fibers are always has low mechanical properties. So that we are planning to increase the composite strength by adding of synthetic fibers because synthetic fibers had high mechanical properties compared to natural fibers. Then we are collected the required synthetic fiber of glass fiber the type of chopper stand with the mat shape for conveniently using when fabrication of composites from, GVR resin and polymer suppliers, Madurai, Tamilnadu. The properties of Glass fiber is given in table 2.
Sci. Technol. Arts Res. J., April-June 2015, 4(2): 241-246

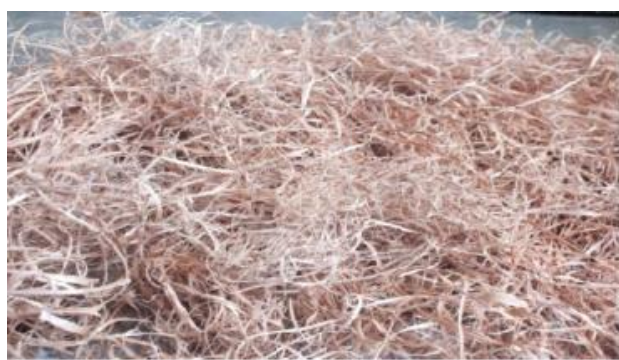

Figure 6: Burmese silk orchid fiber

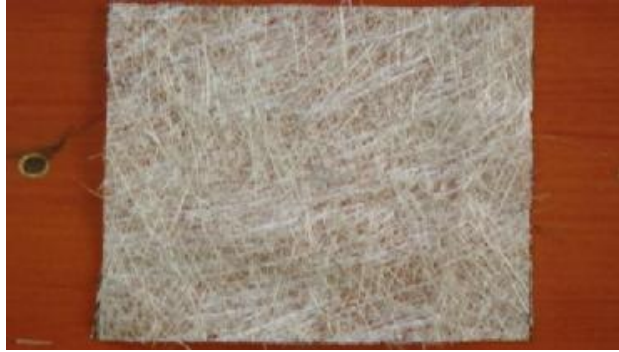

Figure 7: Glass Fiber

Table 2: Glass fiber analysis

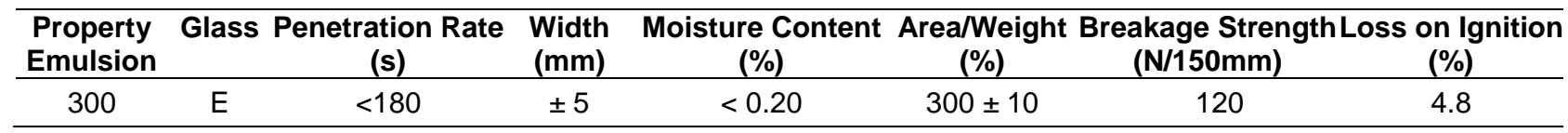

\section{Collection of Resin}

Isophthalic often referred to as Iso, it is improved vinyl ester. It has a slightly higher cost, improved strength, thermal stability $\left(55^{\circ} \mathrm{C}\right)$ and mild resistance to corrosion conditions. Improved resistance to water permeation has prompted its use as a gel barrier coat in marine applications. Improved chemical resistance has led them to extensive use in underground petroleum tanks (in gas stations) with satisfactory service life. They are also used in salts and mild acids. Vinyl ester Even further improved vinyl ester, it is bisphenol chlorinated, or a combination of vinyl ester and epoxy as shown in figure 8. Its curing, handling and processing characteristics are those of vinyl ester, and it exhibits higher test results in corrosion temperature resistance and strength and has higher cost. Modifications of the molecule have produced even higher properties.

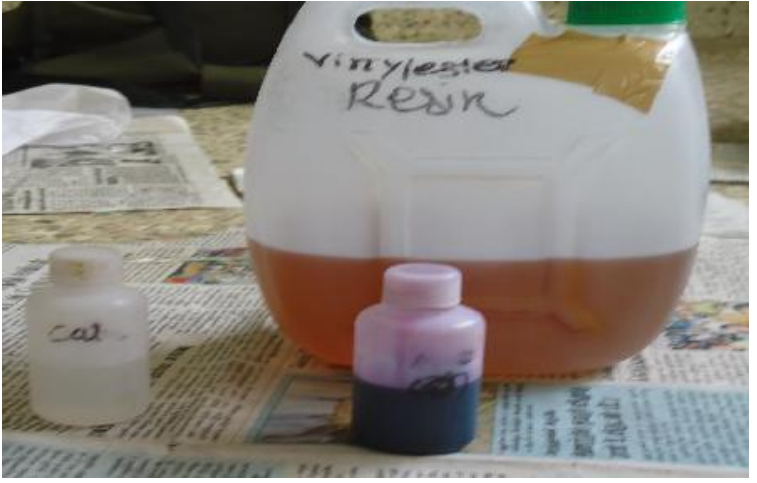

Figure 8: Vinyl ester resin, catalyst and accelerator

Table 3: Vinyl Ester Resin Analysis

\begin{tabular}{clcccc}
\hline S.No & \multicolumn{1}{c}{ Test } & Test Method & Specification & Test Value & Unit \\
\hline 1 & Appearance & Visual & Pale Brownish Liquid & Pale Brownish Liquid & Nil \\
2 & Viscosity at $25{ }^{0} \mathrm{C}$ & IS6746:1994 & $300-450$ & 355 & $\mathrm{cP}$ \\
3 & Density at $25{ }^{0} \mathrm{C}$ & IS6746:1994 & $1.030-1.050$ & 1.048 & $\mathrm{gm}^{3} \mathrm{~cm}^{3}$ \\
4 & Volatile content & IS6746:1994 & $39-45$ & 42.4 & $\%$ \\
5 & Acid Value & IS6746:1994 & $08-12$ & 08.87 & $\mathrm{Mg} \mathrm{KOH} / \mathrm{gm}$ \\
6 & Get time at $25{ }^{\circ} \mathrm{C}$ & IS6746:1994 & $20-30$ & 28 & $\mathrm{~min}$ \\
\hline
\end{tabular}

\section{Resin}

Now -a- days resin and plastics are considered synonymous but the term plastic must be differentiated from the resin. Resins are the basic binding materials, which form a major part of plastics and which actually has undergone polymerization and condensation during their preparation. Resin is the binder, which holds the different constituents together. Thermosetting resins are usually supplied as linear polymers of comparatively low molecular weight because of this stage they are fusible and hence mouldable.

\section{Catalyst}

The conversion of this linear polymer link into cross linked infusible form takes place during moulding the presence of catalyst. The catalyst occur some chemical reactions between inter molecules of resin then converted into thermoset plastics. The correct ratios of catalyst to 
resin by weight $1 \%$ is considered a slow mix, $1.5 \%$ is ideal, $2 \%$ is a fast mix. Additions outside these bands in not advisable for proper curing, in fact adding more than $3 \%$ may result in a failure to cure.

The pot life of these mixes is also determined by temperature. The higher the temperature the faster the cure. As a general guide $1.5 \%$ addition at room temperature gives $45-60$ minutes pot life. The resin will always cure quicker if left in a mass such as the mixing bucket or in castings. The catalyst are depends on the resin so that every resin will be required different catalysts. Here we are using vinyl ester based on thermosetting plastics so that the vinyl ester basically supplied liquid form visually pale brownish.Methyl Ethyl Ketone Peroxide (MEKP) as a catalyst for vinyl ester with $1.5 \%$ weight of resin.

\section{Accelerator}

In that time conversion of resin from linear link and fusible form into cross linked infusible polymer when adding MEKP catalyst the process of conversion will be taken more time. So that we are adding some external agents to hurry up the curing the resin is Accelerators. Here Cobalt Octate $1.5 \%$ weight of resin added as accelerator for fastening the curing process.

\section{Fabrication of Composites}

The composite is made in the mould by hand layup method. In this process resin is added with the accelerator and hardener and pours into the cavity. Then the fiber is sprayed over the resin evenly and again resin is poured on it. After that the mould is closed and the plates are bolted together tightly. The catalyst or accelerator initiates curing in the resin system, which hardens the composite without external heat. The composite of two different compositions i.e. $5 \mathrm{wt} \%$, with three different lengths of chopped fibers (20mm, $30 \mathrm{~mm}$, and $40 \mathrm{~mm}$ ) respectively) is manufactured as shown in figures 9 and 10 .

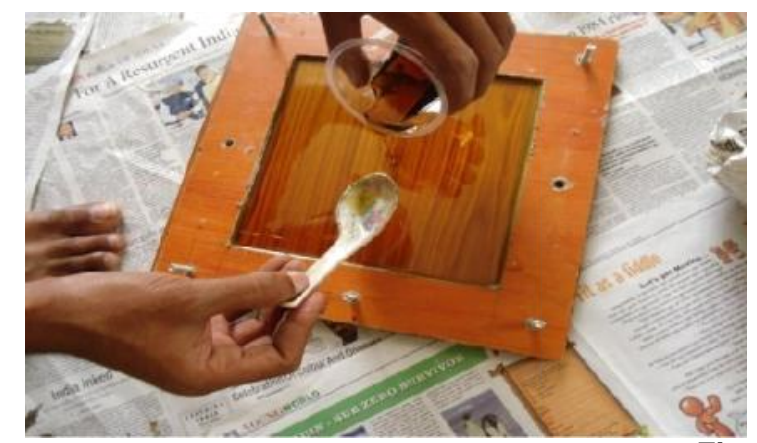

9:

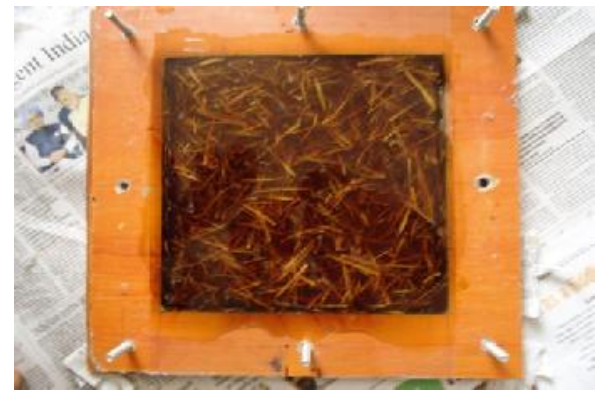

Fabrication of composite step1

Figure10: Fabrication of composite step 2

The base board and the middle board is set with the proper position using bolt and nuts as shown in figures 11 and12. The OHP sheet should be placed between the base and middle boards. Because of the resin will be observed by the boards when moulding so that ohp will be preventing the problem. Then the resin will be leak between the board and OHP sheet. The Glazy putty using to close the gap occurring between them.

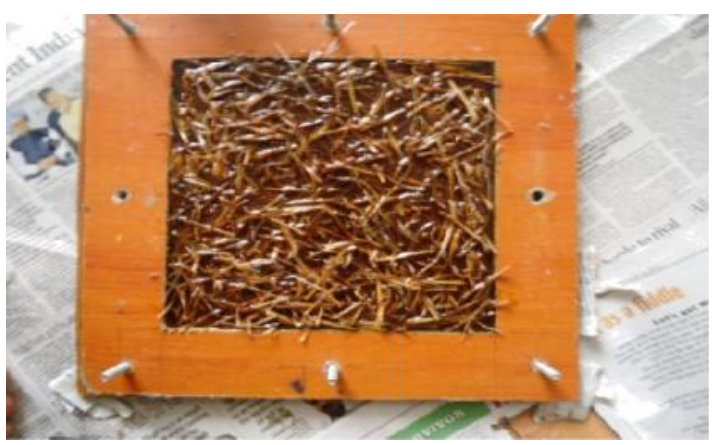

Figure 11: Fabrication of composite step 3

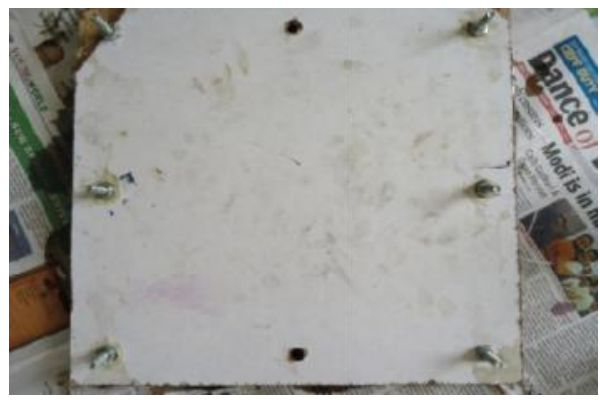

Figure 12: Fabrication of composite step 4

Some amount of resin poured into the cavity such a layer of resin will be form on the OHP sheet. Then we put specimen sized glass fiber into the cavity. The mat shaped glass fiber placed on the resin layer in cavity. Glass fiber immersed in resin with the help of spoon for 1 min. Figures 13 and 14 Shows the glass fiber on resin layer. Then some amount of resin pours on the glass fiber layer.

After that the fabrication step 2 we have to put different length of Burmese silk orchid fibers into the cavity on the glass fiber. The resin should be poured on to the Burmese silk orchid fiber and then making similar surface of fiber layer with the help of spoon.

Another one glass fiber mat placed on the Burmese silk orchid fiber with resin layer. Both outer layer of Burmese silk orchid fiber has covered with glass fibers. Then finally again OHP sheet should be placed on the glass fiber layer due to prevention of resin leakage and glazy appearance of composites. At last the top board to set among the middle board with bolt and nuts. The every nuts are tighted manually using spanners. Some amount of constant load applied on top of the boards.

After 4 hours we will be removed the boards using spanners and taken out the specimen. According to this procedure we were fabricated four no. of samples $A, B, C, D$ by complete resin and adding $5 \%$ weight of fiber to vary the length $20 \mathrm{~mm}, 30 \mathrm{~mm}, 40 \mathrm{~mm}$ respectively. 
Lakshmanan, Ramesh Kumar and Gopal

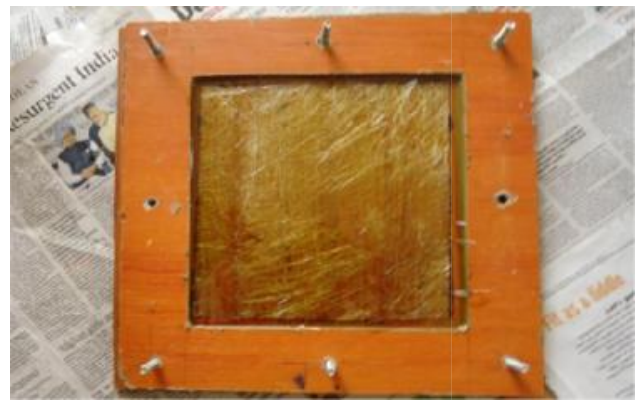

Figure 13: Fabrication of composite step 5

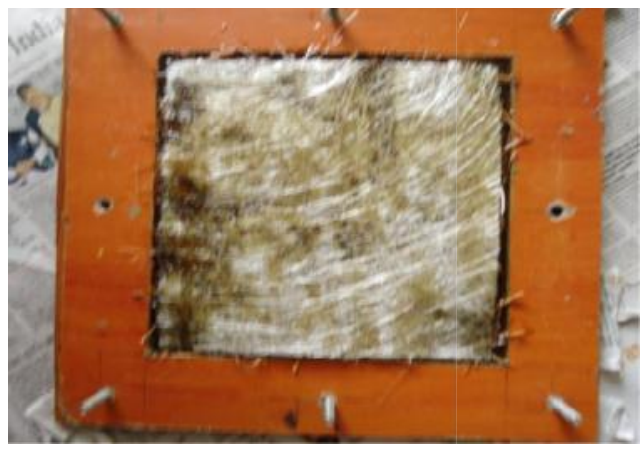

Figure 14: Fabrication of composite step 6

\section{Mechanical Testing} Tensile Test

Ultimate tensile strength, often shortened to tensile strength or ultimate strength, is the maximum stress that a material can withstand while being stretched or pulled before failing or breaking (Vasantha et al., 2013). The tensile test is generally performed on flat specimens. The commonly used specimens for tensile test are the dogbone type and the straight side type with end tabs.

During the test a uniaxial load is applied through both the ends of the specimen. American Standard Testing and Measurement (ASTM) method D638 for tensile properties of fiber resin composites. The length of the test section should be $165 \mathrm{~mm}$ and the width should be $19 \mathrm{~mm}$ for the thickness of $5 \mathrm{~mm}$ as shown in figure 15 .
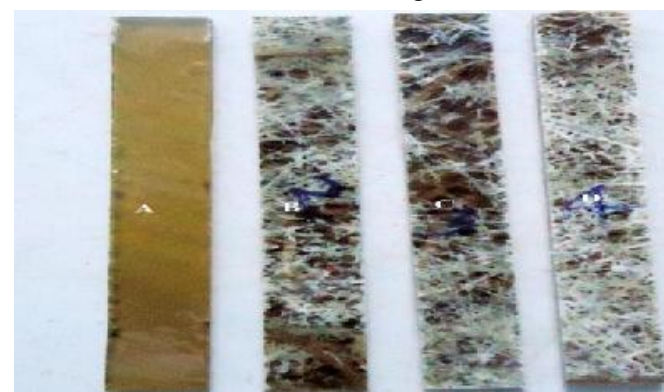

Figure 15: Samples of tensile test standards

The tensile test is performed in the Tinius Olsen H50KS standard tensile properties testing machine for plastics with the cross head speed of $2 \mathrm{~mm} / \mathrm{min}$ and results are analyzed to optimize the tensile strength of composite samples. Samples are marked $25 \mathrm{~mm}$ from both edges for grip. After tensile test conducted the samples were braked in their cross section. In Figure 16 shows the samples after testing of tensile the arrow mark indicated the braking point at the composite samples A,B,C,D. sample A only brake into two pieces because of the sample $A$ fabricated by complete resin only. So that composite sample braked easily at low stress.
Sci. Technol. Arts Res. J., April-June 2015, 4(2): 241-246

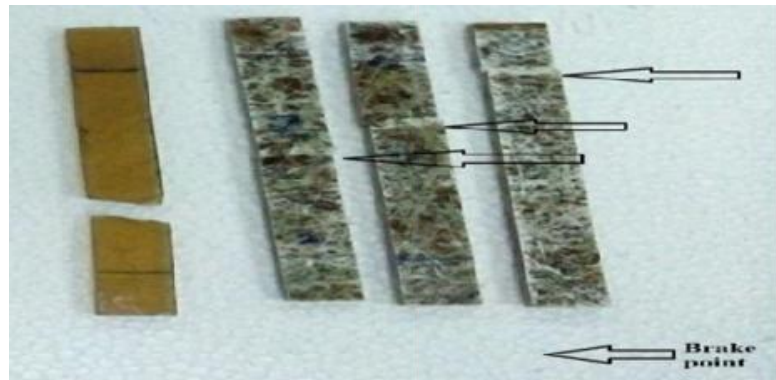

Figure 16: Samples A, B, C, D after tensile test

\section{Flexural Test}

Flexural strength, also known as modulus of rupture, bend strength, or fracture strength, a mechanical parameter for brittle material, is defined as a material's ability to resist deformation under load. The transverse bending test is most frequently employed, in which a specimen having either a circular or rectangular crosssection is bent until fracture or yielding using a three point flexural test technique. The flexural strength represents the highest stress experienced within the material at its moment of rupture (Velmurugan et al., 2007). The short beam shear (SBS) tests are performed on the composite samples at room temperature to evaluate the value of flexural strength (FS). It is a 3-point bend test, which generally promotes failure by inter-laminar shear. The SBS test is conducted as per ASTM standard D790-10 the standard test method for flexural properties of unreinforced and reinforced plastics. Span length of 170 $\mathrm{mm}$ with the width of $50 \mathrm{~mm}$ and the cross head speed of $2 \mathrm{~mm} / \mathrm{min}$ are maintained as shown in figure 17.
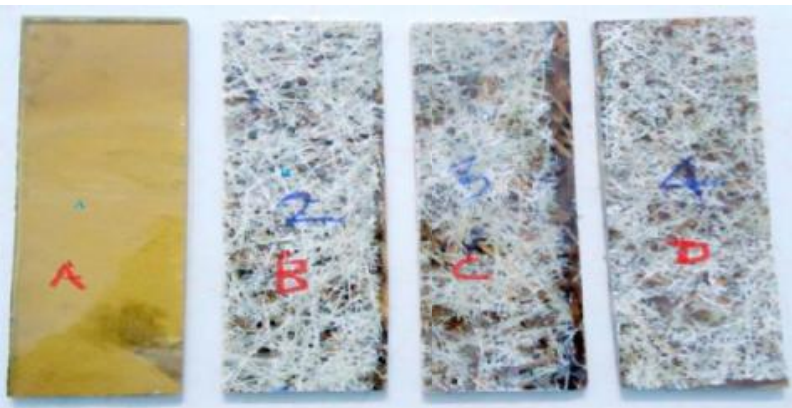

Figure 17: Samples of flexural test standard

After bending test conducted the samples were broken in their cross section. Figure 18 shows the samples after testing of flexural the arrow mark indicated the breaking point at the composite samples $A, B, C, D$. sample $A$ only brake into two pieces because of the sample $A$ fabricated by complete resin only. So that composite sample braked easily at low stress.

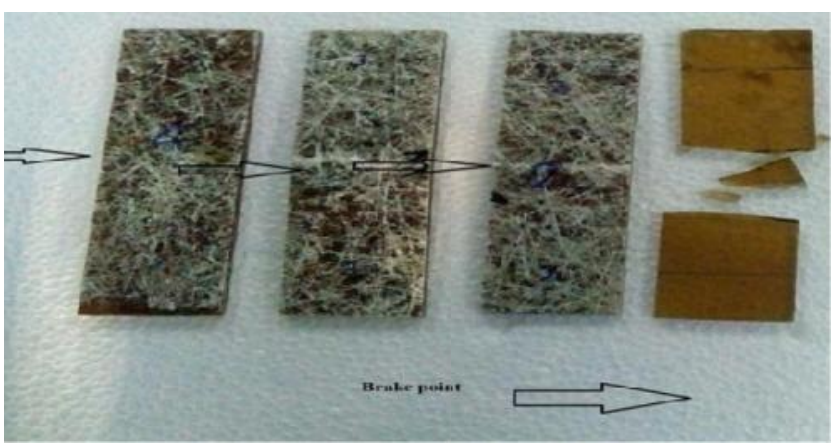

Figure 18: Samples $A, B, C, D$ after flexural test 


\section{RESULTS AND DISCUSSION}

A gradual increase in tensile strength as well as flexural strength with the weight fraction of fiber is noticed.
It clearly indicates that inclusion of fiber improves the load bearing capacity and the ability to withstand bending of the composites.

Table 4: Tensile and flexural strength

\begin{tabular}{ccccccc}
\hline $\begin{array}{c}\text { Fiber } \\
\text { content }\end{array}$ & Samples & $\begin{array}{c}\text { Tensile } \\
\text { strength }\end{array}$ & $\begin{array}{c}\text { Youngs } \\
\text { modulus }\end{array}$ & $\begin{array}{c}\text { Elongation } \\
\text { of break }\end{array}$ & $\begin{array}{c}\text { Flexural } \\
\text { strength }\end{array}$ & $\begin{array}{c}\text { Flexural } \\
\text { modulus }\end{array}$ \\
\hline (Wt \%) & & MPa & GPa & $(\%)$ & MPa & GPa \\
\hline & $\mathrm{A}$ & 21.4 & 1.289 & 1.66 & 23.0 & 2.017 \\
5 & $\mathrm{~B}$ & 24.2 & 1.359 & 1.78 & 77.3 & 6.039 \\
& $\mathrm{C}$ & 26.5 & 1.409 & 1.88 & 87.6 & 4.893 \\
& $\mathrm{D}$ & 27.5 & 0.897 & 3.70 & 93.8 & 5.936 \\
\hline
\end{tabular}

It may be mentioned here that both tensile and flexural strengths are important for recommending any composite as a candidate for structural applications. Here the sample $A$ is fabricated with complete resin and B,C,D samples are fabricated by adding $5 \%$ of fiber with different lengths $20 \mathrm{~mm}, 30 \mathrm{~mm}, 40 \mathrm{~mm}$ respectively as shown in table 4 .

\section{CONCLUSIONS}

Burmese silk orchid fiber and glass fiber reinforced vinyl ester matrix is successfully fabricated by hand layup method. This hand layup moulding method is economically better when compared to compression moulding composite fabrication. Natural fibers are not convenient for load applications because of the natural fibers are always has low mechanical properties .so that we are plan to increase the composite strength by adding of synthetic fiber (glass fiber) because synthetic fibers had high mechanical properties when compared to natural fibers.

Burmese silk orchid and glass fiber reinforced with vinyl ester resin composite has not been studied. There is a very wide scope for future scholars to explore this area of research. Many other aspects of this problem like effect of fiber orientation, loading pattern, weight fraction of ceramic fillers on wear response of such composites require further investigation.

\section{Conflict of Interest}

All the authors declared no conflict of interest.

\section{REFERENCES}

Ali I. Al-Mosawi., Mohammad H. Al-Maamori and Zaynab A. Wetwet (2012). Mechanical properties of composite material reinforcing by natural-synthetic fibers. Academic Research International 3(3): 108-112.

Daiane Romanzini., Alessandra Lavoratti., Heitor L. Ornaghi Jr., Sandro C. Amico and Ademir J. Zattera (2013). Influence of fiber content on the mechanical and dynamic mechanical properties of glass/ ramie polymer composites. Materials and Design 47(1): 9-15.

Girisha, C., Sanjeevamurthy and Gunti Rangasrinivas (2012). Tensile properties of natural fiber-reinforced epoxy-hybrid Composites. International Journal of Modern Engineering Research, 2(2): 471-474.

José Humberto., Santos Almeida Júnior., Heitor Luiz Ornaghi Júnior., Sandro Campos Amico and Franco Dani Rico Amado (2012). Study of hybrid intralaminate curaua/glass composites. Materials and Design 42(1): 111-117.

Saha,. R, Morris, E. and Chawla, E. (2012). Hybrid and conventional particle reinforced metal matrix composites by squeeze infiltration casting. Journal of Materials Science 21(1): 337-339.

Vasanta V. Cholachagudda., Udayakumar, P.A. and Ramalingaiah (2013). Mechanical characterisation of coir and rice husk reinforced hybrid polymer composite. International Journal of Innovative Research in Science, Engineering and Technology 2(8): 3779-3786.

Velmurugan, R. and Manikandan, V. (2007). Mechanical properties of palmyra/glass fiber hybrid composites. Compoistes A 38(10): 2216-2226. 